\title{
Erratum to: Progress of p-channel bottom-gate poly-Si thin-film transistor by nickel silicide seed-induced lateral crystallization
}

Sol Kyu Lee ${ }^{1}$ - Ki Hwan Seok ${ }^{1}$ Jae Hyo Park ${ }^{1} \cdot$ Hyung Yoon Kim ${ }^{1}$.

Hee Jae Chae $^{1} \cdot$ Gil Su Jang ${ }^{1}$ Yong Hee Lee ${ }^{1} \cdot$ Ji Su Han $^{1} \cdot$ Seung Ki Joo ${ }^{1}$

Published online: 14 June 2016

(C) Springer-Verlag Berlin Heidelberg 2016

Erratum to: Appl. Phys. A (2016) 122:613

DOI 10.1007/s00339-016-0133-5

The original version of this article unfortunately contained a mistake. The presentation of Figs. 5 and 6 was incorrect. The correct Figs. 5 and 6 are given here.

The original article was corrected.

The online version of the original article can be found under doi:10.1007/s00339-016-0133-5.

Seung Ki Joo

skjoo@snu.ac.kr

1 Department of Materials Science and Engineering, Seoul

National University, Seoul 151-742, Republic of Korea 


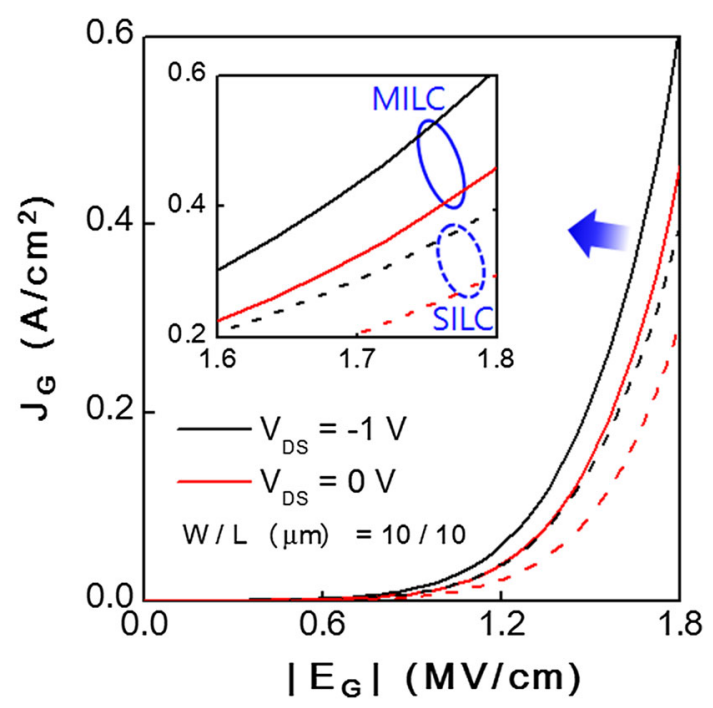

Fig. 5 Gate leakage current densities $\left(J_{\mathrm{G}}\right)$ as a function of absolute value of the gate electric field $\left(E_{\mathrm{G}}\right)$ of MILC and SILC-BGPS TFTs

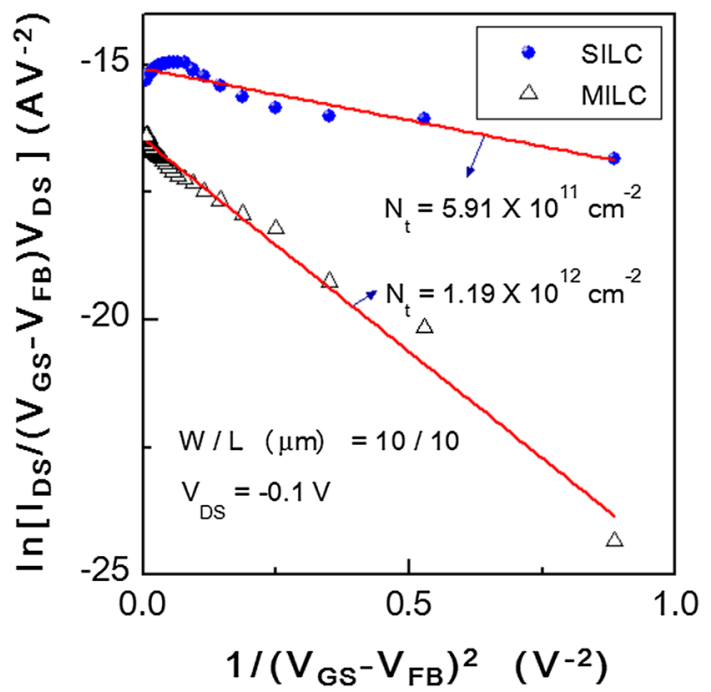

Fig. 6 Proano plot and grain boundary trap-state densities of MILC and SILC-BGPS TFTs 